\title{
The Question Game: A learning through play experience
}

\author{
Keywords \\ collective challenges, exams, learning, play, school
}

The following work is informed by and exploration bridging biological anthropology with education. The design of this educational experience is grounded on Humberto Maturana's 'culturalbiology'. The panoramic perspective of "The evolution of learning" gave us a new vision about the importance of Teaching, as a tool for collaborative challenges. We realized that the main hurdle on "alternative education" is the final exams that the Ministry of Education of Chile asks at the end of the year. In order to prepare our students with the National Curriculum, all the ideas of play and creativity were subordinated to this aim. Our proposal is to understand "the final exams" as a collective challenge of the whole school, including the students, and use all "learning through play" strategies where older children could teach and facilitate learning to the younger children. Based on this, we designed "The Question Game", a board game which is run by several teams of 4 children of different ages each. They need to roll the dice and find the question that the dices show. Teachers give the questions that we collect directly from the "final exams" format. They take the question that needs to be solved in group, then if the answer is right, we give a sticker to the group, and they continue until they solve all the questions for that week. Then we have a moment to share the experience with the other teams and promote the concept that the school as a whole can solve all the challenges. For example, we give incentives for all the school like a day at the beach or in the forest. Our education design is based on transforming the logic of "Individual" "year" "exams" and transforming it into a "Playful" "collective" "day to day" activity. We embodied this concept using the enaction principles of learning with the body, then we design the space in order that children are moving continuously from their desk to the teachers' place, interacting with other students. The economic cost to implement this game is very accessible, and easy to implement (the main inputs are paper, pencils and stickers). These ideas and educational design are deeply rooted in the Santiago School of Cognition. We boost what children learn with social interaction with their peers and also by moving their body with high frequency. Finally, using "Teaching" as a tool is critical, because it is an application that cognitive knowledge is a social coordination, and promoting children teach each other, is a way to give a practical relevance of the information in their lives, and then reinforce motivation to really learn. 